\title{
Regioselectivity and kinetics of fluorination of alkyl substituted phenols by $N$-fluoro-1,4-diazoniabicyclo[2.2.2]octane salt analogues
}

\author{
Marjan Jereb, Marko Zupan, and Stojan Stavber*
}

Laboratory for Organic and Bioorganic Chemistry, “Jozef Stefan” Institute and Department of Chemistry of the Faculty for Chemistry and Chemical Technology of the University of Ljubljana, Jamova 39, 1000 Ljubljana, Slovenia

E-mail: stojan.stavber@ijs.si

\section{Dedicated to Prof. Branko Stanovnik on the occasion of his $65^{\text {th }}$ birthday}

(received 17 June 03; accepted 09 Jan 04; published on the web 22 Jan 04)

\begin{abstract}
The 3,4-dialkylsubstituted phenols: 3,4-dimethylphenol, 5-indanol, and 5,6,7,8-tetrahydro-2naphthol were used as target molecules for fluorination with the $N$-fluoro-1,4diazoniabicyclo[2.2.2] octane salt analogues Selectfluor ${ }^{T M}$ F-TEDA and Accufluor ${ }^{T M}$ NFTh. 4Fluoro-3,4-dialkylcyclohexa-2,5-dienone derivatives, as the result of an addition-elimination process, were the main, and 2-fluoro- and 6-fluoro-3,4-dialkylphenols derivatives resulting from a substitution reaction, the minor products of the fluorination process. The type of transformation was found to be independent of the structure of starting material and reagent, while these two parameters were important for the regioselectivity of the substitution reaction. The effect of the solvent on these reactions was evaluated, second order kinetics for the fluorination with F-TEDA in $\mathrm{MeCN}$ was established, rate konstants $\mathrm{k}_{2}$ were measured, and thermodynamic parameters for the transition state $\left(\Delta \mathrm{H}^{*}, \Delta \mathrm{S}^{*}\right.$, and $\left.\Delta \mathrm{G}^{*}\right)$ determined. A reaction pathway postulating a SET process as the key step was proposed.
\end{abstract}

Keywords: Phenols, fluorination, kinetics, Selectfluor ${ }^{\mathrm{TM}}$, Accufluor $^{\mathrm{TM}}$

\section{Introduction}

The introduction, followed very soon after by the broad synthetic application, of organic molecules incorporating reactive a $N$-F bond as versatile, site-selective and mild fluorinating reagents $^{1}$ represents one of the most important break-throughs in the last decade, reviving a strong impetus to related areas of chemistry, which are of considerable general interest to the basic and applied research community. ${ }^{2}$ Very soon after their promotion, ${ }^{3}$ derivatives of $N$ - 
fluoro-1,4-diazoniabicyclo[2.2.2] octane salts became one of the most popular groups of these compounds, particularly 1-chloromethyl-4-fluoro-1,4-diazoniabicyclo[2.2.2]octane bis(tetrafluoroborate) (Selectfluor ${ }^{T M}$ F-TEDA 1a) which is actually one of the most often used siteselective fluorinating reagent. Its 1-fluoro-4-hydroxy- (Accufluor ${ }^{T M} \mathrm{NFTh}, \mathbf{1 b}$ ) or 1,4-difluorosubstituted analogues, mainly due to their higher cost, achieved a lower commercial success. As well as being versatile fluorine atom transfer reagents, $N$-F compounds are also moderate to strong oxidants, ${ }^{4}$ and F-TEDA and NFTh are the strongest among them. ${ }^{5}$ Therefore we can expect a certain decrease in the selectivity of their reactions with target molecules bearing oxidisable functional groups or heteroatoms. Hydroxy groups bonded to an aromatic ring conveys a great deal of potential fluorofunctionalisation/oxidation competitive dualism and can represent a considerable selectivity diminishing factor, so that this issue still calls for further research. In our continuing interest in the reactions of $N$-F compounds with phenols ${ }^{6}$ we now report further investigations of the reactions of alkyl substituted phenols with Selectfluor ${ }^{T M} \mathrm{~F}$ TEDA and Accufluor ${ }^{T M}$ NFTh.

\section{Results and Discussion}

3,4-Dialkyl substituted phenols have often been used as target molecules for evaluation and comparative characterisation of reagents and methods for halogenation of aromatic molecules. For this purpose 3,4-dimethyl phenol (2a), 5-indanol (2b) and 5,6,7,8-tetrahydro-2-naphthol (2c) are the most convenient tools, already used by Mills and Nixon in 1930 in their elaboration of the nonequivalency of two ortho positions for electrophilic substitution, ${ }^{7}$ known as the Mills-Nixon effect. The same targets were used in investigations of the bromination of phenols with elemental bromine, ${ }^{8}$ chlorination with chlorine ${ }^{9 \mathrm{a}}$ or $\mathrm{SbCl}_{5}, 9 \mathrm{~b}, 9 \mathrm{c}$ and oxidative fluorination with an $\mathrm{HF} /$ pyridine mixture using $\mathrm{PbO}_{2}{ }^{10 \mathrm{a}}$ or phenyliodo(III) bis(trifluoroacetate) ${ }^{10 \mathrm{~b}}$ as oxidants.

In a typical experiment we stirred a solution of starting phenol $\mathbf{2}$ and fluorinating reagent $\mathbf{1}$ in acetonitrile at room temperature for 4.5 hours and after analysis of the crude reaction mixture obtained, established that the starting material was almost quantitatively transformed to three fluorinated products. The main product was identified as the 4-fluoro functionalised derivative of substituted cyclohexa-2,5-dienone 3, while the minor two were recognised as fluoro substituted phenols bearing a fluorine atom bonded at ortho positions 2 and 6 . From the relative distribution of the products of these reactions (Table 1), we can conclude that the most electron-rich positions of target molecules 2 were fluorofunctionalised and that para attack was considerably predominant over ortho one. The addition-elimination process, forming 4-fluoro-3,4-dialkylcyclohexa-2,5-dienone derivatives 3a-c, was in these cases found to be much more pronounced than the substitution process resulting in 2-fluoro (4a-c) and 6-fluoro-3,4-dialkylphenols (5a-c). 
Table 1. Fluorination of 3,4-dialkyl-substituted phenols with derivatives of $N$-fluoro-1,4diazoniabicyclo[2.2.2] octane bis(tetrafluoroborate) ${ }^{\text {a) }}$

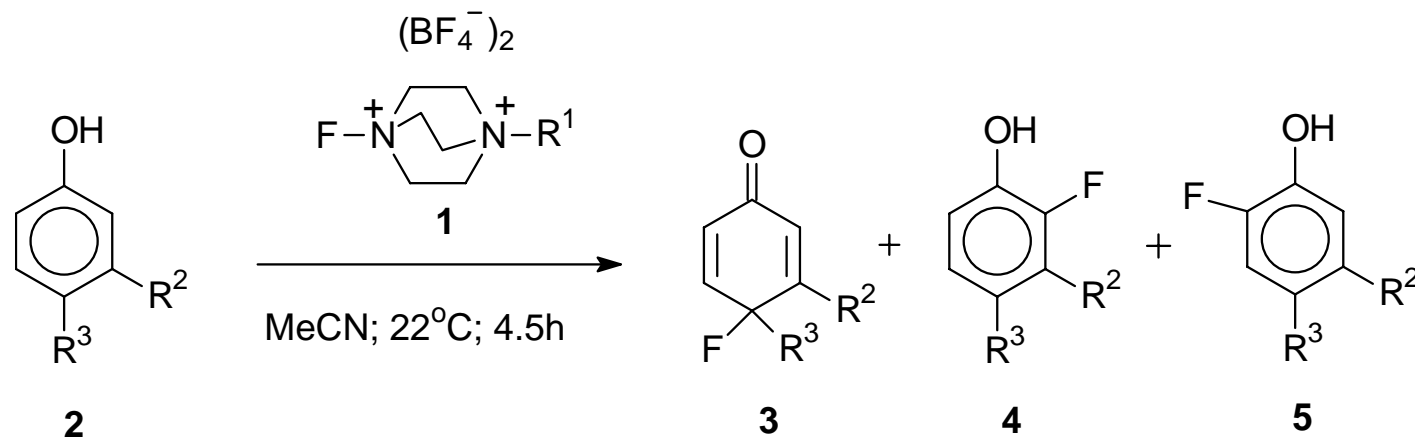

$\begin{gathered}\text { Relative ratio between types of } \\ \text { transformations }(\mathbf{3}: \mathbf{4}+\mathbf{5})^{\mathrm{b})} \\ \mathrm{NFTh}\end{gathered}$
$\begin{gathered}\text { Regioselectivity of the } \\ \text { F-TEDA }\end{gathered}$
F-TEDAtitution $(\mathbf{4}: \mathbf{5})$

a) 1a: $\mathrm{R}^{1}=\mathrm{CH}_{2} \mathrm{Cl}$; Selectfluor ${ }^{T M}$ F-TEDA; 1b: $\mathrm{R}^{1}=\mathrm{OH}$; Accufluor ${ }^{T M} N F T h .{ }^{\text {b) }}$ Determined from the ${ }^{19} \mathrm{~F}$ NMR spectra of the crude reaction mixture; overall yield of fluorinated products (9398\%) was determined using octafluoronaphthalene(OFN) as internal standard.

The structure of the target phenols $\mathbf{2 a - c}$, as well as of the fluorinating reagents $\mathbf{1 a}, \mathbf{b}$, has no effect on the type of the transformation, while these two parameters play important roles in the course of the substitution process. In the case of 3,4-dimethylphenol 2a the ratio between 6- and 2-fluorination was about two, in 5-indanol $\mathbf{2 b}$ this ratio was even higher, but in the case of 5,6,7,8-tetrahydro-2-naphthol $\mathbf{2 c}$ the opposite regioselectivity was observed and 2-fluoro derivative $4 \mathbf{a}$ found as the main product of the substitution reaction. These observations are very 
similar to those established for the bromination of dialkyl substituted phenols, ${ }^{8 \mathrm{a}}$ and are in agreement with the relative reactivity expressed by partial rate factors for electrophilic displacement at both positions. ${ }^{12}$

Table 2. Effect of the solvent on the fluorination ${ }^{\text {a) }}$ of 3,4-dimethylphenol 2a with F-TEDA and NFTh

\begin{tabular}{|c|c|c|c|c|c|}
\hline \multirow{2}{*}{\multicolumn{2}{|c|}{ Solvent }} & \multicolumn{2}{|c|}{$\begin{array}{l}\text { Relative ratio between types of } \\
\text { transformation }^{\text {b) }}(\mathbf{3 a}: \mathbf{4 a}+\mathbf{5 a})\end{array}$} & \multicolumn{2}{|c|}{$\begin{array}{c}\text { Overall yield }(\%)^{\mathrm{c})} \\
\mathbf{3 a}+\mathbf{4 a}+\mathbf{5 a}\end{array}$} \\
\hline & & F-TEDA & NFTh & F-TEDA & NFTh \\
\hline \multicolumn{2}{|l|}{$\mathrm{MeCN}$} & $85: 15$ & $84: 16$ & 96 & 93 \\
\hline \multirow[t]{4}{*}{$\mathrm{MeCN} / \mathrm{MeOH}$} & $9.5: 0.5$ & $85: 15$ & $84: 16$ & 81 & 80 \\
\hline & $8: 2$ & $76: 16^{\mathrm{d})}$ & $82: 18$ & 75 & 75 \\
\hline & $7: 3$ & $72: 17$ & $79: 21$ & 75 & 62 \\
\hline & $4: 6$ & $52: 20$ & $59: 31$ & 49 & 47 \\
\hline \multicolumn{2}{|l|}{$\mathrm{MeOH}$} & / & $56: 26$ & 0 & 52 \\
\hline \multirow[t]{2}{*}{$\mathrm{MeCN} / \mathrm{H}_{2} \mathrm{O}$} & $9: 1$ & $76: 24$ & $77: 23$ & 70 & 75 \\
\hline & $1: 1$ & $66: 34$ & $65: 35$ & 23 & 32 \\
\hline \multirow[t]{3}{*}{$\mathrm{MeCN} / \mathrm{CH}_{2} \mathrm{Cl}_{2}$} & $9: 1$ & $81: 19$ & $82: 18$ & 90 & 80 \\
\hline & $7: 3$ & $80: 20$ & $82: 18$ & 79 & 47 \\
\hline & $4: 6$ & $75: 25$ & $75: 25$ & 17 & 13 \\
\hline \multicolumn{2}{|l|}{$\mathrm{CH}_{2} \mathrm{Cl}_{2}$} & 1 & l & 0 & 0 \\
\hline \multicolumn{2}{|c|}{$\mathrm{CF}_{3} \mathrm{CH}_{2} \mathrm{OH}$} & l & / & 0 & 0 \\
\hline \multicolumn{2}{|c|}{$\mathrm{MeO}\left(\mathrm{CH}_{2}\right)_{2} \mathrm{OH}$} & $85: 15$ & $79: 21$ & 60 & 75 \\
\hline
\end{tabular}

a) Standard reaction conditions: $1 \mathrm{mmol}$ of $\mathbf{2 a}, 1 \mathrm{mmol}$ of $\mathbf{1}, 10 \mathrm{~mL}$ of solvent, $22^{\circ} \mathrm{C}, 4.5 \mathrm{~h} .{ }^{\text {b) }}$ Determined from the ${ }^{19} \mathrm{~F}$ NMR spectra of the crude reaction mixture. ${ }^{\mathrm{c})}$ Determined from the ${ }^{19} \mathrm{~F}$ NMR spectra of the crude reaction mixture using OFN as internal standard and calculated to starting material. ${ }^{\mathrm{d})}$ Undefined product $(\delta \mathrm{F}=-163 \mathrm{ppm}(\mathrm{m}))$ started to form.

We further studied the effect of the solvent on the fluorination reactions and the data obtained with 3,4-dimethylphenol $\mathbf{2 a}$ as the target are collected in Table $\mathbf{2}$. It is evident from these data that neither protic nor non-polar solvents do not stimulate the fluorination process. The relative amounts of fluorinated 3,4-dimethylphenols $4 \mathbf{a}$ and $\mathbf{5 a}$ increased with increasing protic character of the solvent and with decrease in its polarity, but the overall yield of 
fluorinated products dropped considerably. Since F-TEDA and NFTh are less soluble in these solvents than in acetonitrile, this finding seems to be reasonable. On the other hand, we did not observe the formation of 4-hydroxy or 4-alkoxy substituted derivatives of 3,4dimethylcyclohexa-2,5-dienone as a result of the attack of an external nucleophile, as was the case when 2,4,6-trialkyl substituted phenols ${ }^{6 \mathrm{~d}, 6 \mathrm{e}}$ were used as starting molecules.

We further investigated the kinetics of these transformations and established that in the case of the use of F-TEDA as reagent the reaction rates obey the simple second-order rate equation

$$
\text { d[F-TEDA }] / d t=k_{2}[\text { F-TEDA }] x[\text { phenol 2] }
$$

The second-order rate constants, measured by following the consumption of F-TEDA by iodometric titration, are collected in Table 3 and Table 4 and we can see that the structure of starting phenol $\mathbf{2}$ has a considerable effect on the reaction rates. 5-Indanol $\mathbf{2 b}$ reacts 1.6 times faster than its acyclic analogue $\mathbf{2 a}$, while additional acceleration of the reaction was observed in the case of 5,6,7,8-tetrahydro-2-naphthol 2c which reacts two times faster than $\mathbf{2 a}$. The thermodynamic parameters for the transition state of the reaction collected in Table $\mathbf{4}$ are also instructive. The energies of activation $\Delta \mathrm{H}^{*}$ for the fluorination of 3,4-dimethylphenol $\mathbf{2 a}$ and of 5-indanol have almost the same value, while $\Delta \mathrm{H}^{*}$ for 5,6,7,8-tetrahydro-2-naphthol $2 \mathrm{c}$ is $4 \mathrm{~kJ} / \mathrm{mol}$ lower. This difference in the activation barrier obviously can be attributed to the activation entropy $\Delta S^{*}$ which was found to have a negative sign but its lowest numerical value for the fluorination of 5-indanol $\mathbf{2 b}$ and its highest for the transformation of 5,6,7,8-tetrahydro-2naphthol 2c. A reasonable explanation for this fact would be that in the case of 5-indanol strain between the aromatic and acyclic rings caused a lower degree of order in the activation complex in comparison with 5,6,7,8-tetrahydro-2-naphthol $\mathbf{2 c}$, where the more flexible six-membered ring releases these tensions. As the consequence of all this is that the free energy of activation $\Delta \mathrm{G}^{*}$ has almost the same value for all three reactions.

The reaction pathway for the transformations of phenols with $N$-fluoro-1,4diazoniabicyclo[2.2.2] octane salts analogues has been elaborated and discussed in our previous work. $^{6 \mathrm{~d}, 6 \mathrm{e}}$ We believe that in the case of the fluorination of 3,4-dialkyl substituted phenols 2 with F-TEDA or NFTh a single electron transfer (SET) reaction pathway is also the most likely reaction channel through which phenols 2 are tranformed to products $\mathbf{3}, \mathbf{4}$, and $\mathbf{5}$, with $\mathbf{1}$ and the primarily formed cation radical species further transforming to cationic species, being the reactive intermediates involved in these transformations (Scheme).

Table 3. Effect of the structure of 3,4-dialkyl-substituted phenols $\mathbf{2 a - c}$ on the rate of fluorination with F-TEDA ${ }^{\text {a) }}$
Phenol 2
$\mathrm{k}_{2}(\mathrm{~L} / \mathrm{mol} \mathrm{s})$
$\mathrm{k}_{\mathrm{rel}}=\mathrm{k} / \mathrm{k}_{2 \mathrm{a}}$

3,4-Dimethylphenol 2a

$1.21 \times 10^{-2}$

1.0 


\begin{tabular}{cll}
\hline 5-Indanol 2b & $1.93 \times 10^{-2}$ & 1.6 \\
5,6,7,8-Tetrahydro-2-naphthol 2c & $2.53 \times 10^{-2}$ & 2.1 \\
\hline
\end{tabular}

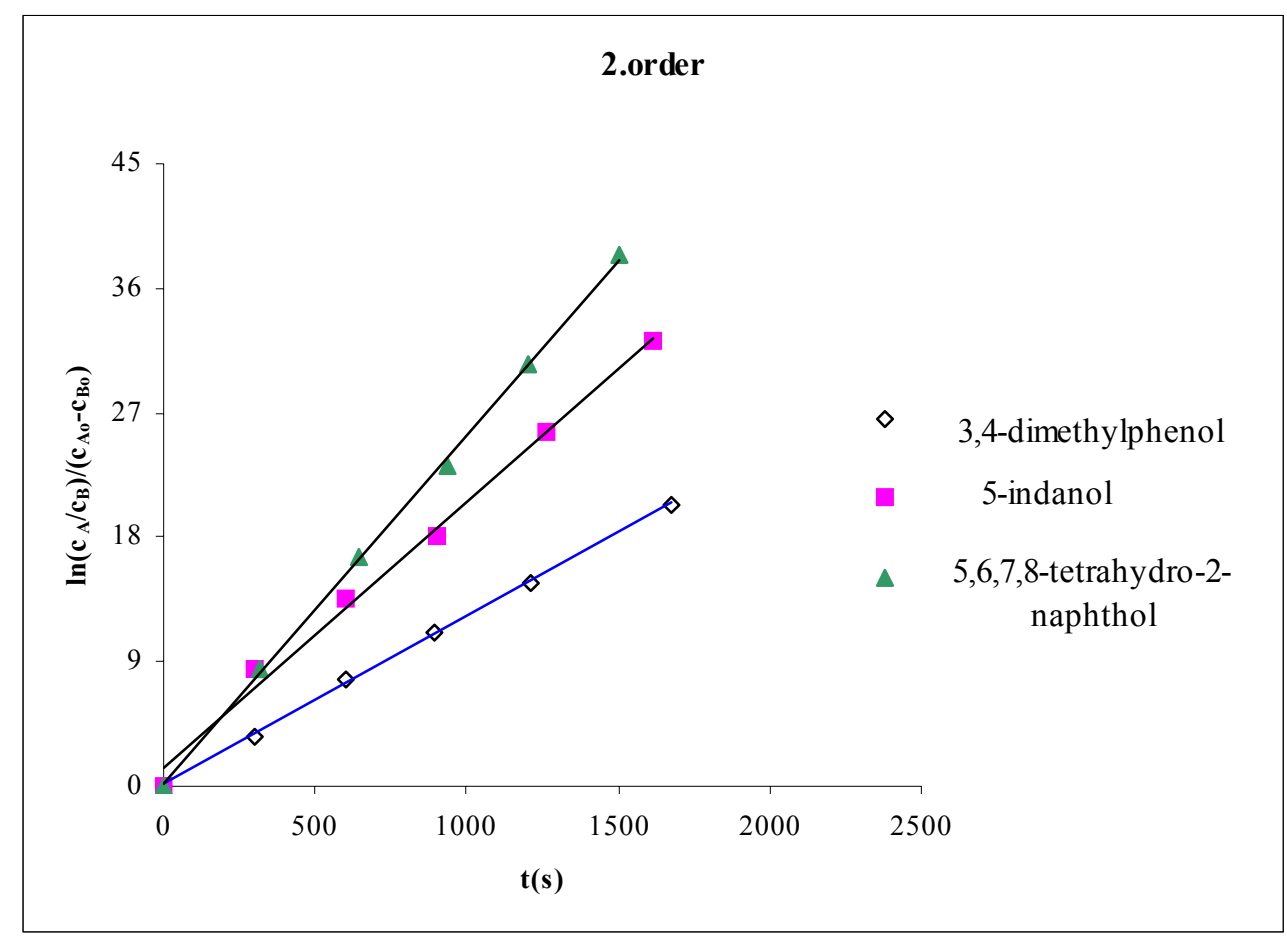

a) Solvent: $\mathrm{MeCN} ; \mathrm{T}=20.1^{\circ} \mathrm{C} ; \mathrm{C}_{\mathrm{phenol}}=2 \times 10^{-2} \mathrm{~mol} / \mathrm{L}$. 
Table 4. Thermodynamic parameters for the transition state for the fluorination of 3,4-dialkylsubstituted phenols 2a-c with F-TEDA in MeCN

\begin{tabular}{lccccc}
\hline Phenol 2a-c & $\begin{array}{c}\mathrm{T} \\
\left({ }^{\circ} \mathrm{C}\right)\end{array}$ & $\mathrm{k}_{2}(\mathrm{~L} / \mathrm{mol} \mathrm{s})$ & $\begin{array}{c}\Delta \mathrm{H}^{*} \\
(\mathrm{~kJ} / \mathrm{mol})\end{array}$ & $\Delta \mathrm{S}^{*}(\mathrm{~J} / \mathrm{K} \mathrm{mol})$ & $\begin{array}{c}\Delta \mathrm{G}^{*} \\
(\mathrm{~kJ} / \mathrm{mol})\end{array}$ \\
\hline & 15 & $6.9 \times 10^{-3}$ & & & \\
& 20 & $1.2 \times 10^{-2}$ & 73.8 & -29.8 & 82.4 \\
3,4-Dimethylphenol 2a & 25 & $2.0 \times 10^{-2}$ & & & \\
\hline & 10 & $5.9 \times 10^{-3}$ & & & \\
5-Indanol 2b & 15 & $1.1 \times 10^{-2}$ & & & \\
& 20 & $1.9 \times 10^{-2}$ & 74.1 & -23.4 & 81.0 \\
& 10 & $8.7 \times 10^{-3}$ & & & \\
5,6,7,8-Tetrahydro-2-naphthol 2c & 15 & $1.5 \times 10^{-2}$ & & & \\
& 20 & $2.5 \times 10^{-2}$ & 70.0 & -36.3 & 81.0 \\
\hline
\end{tabular}

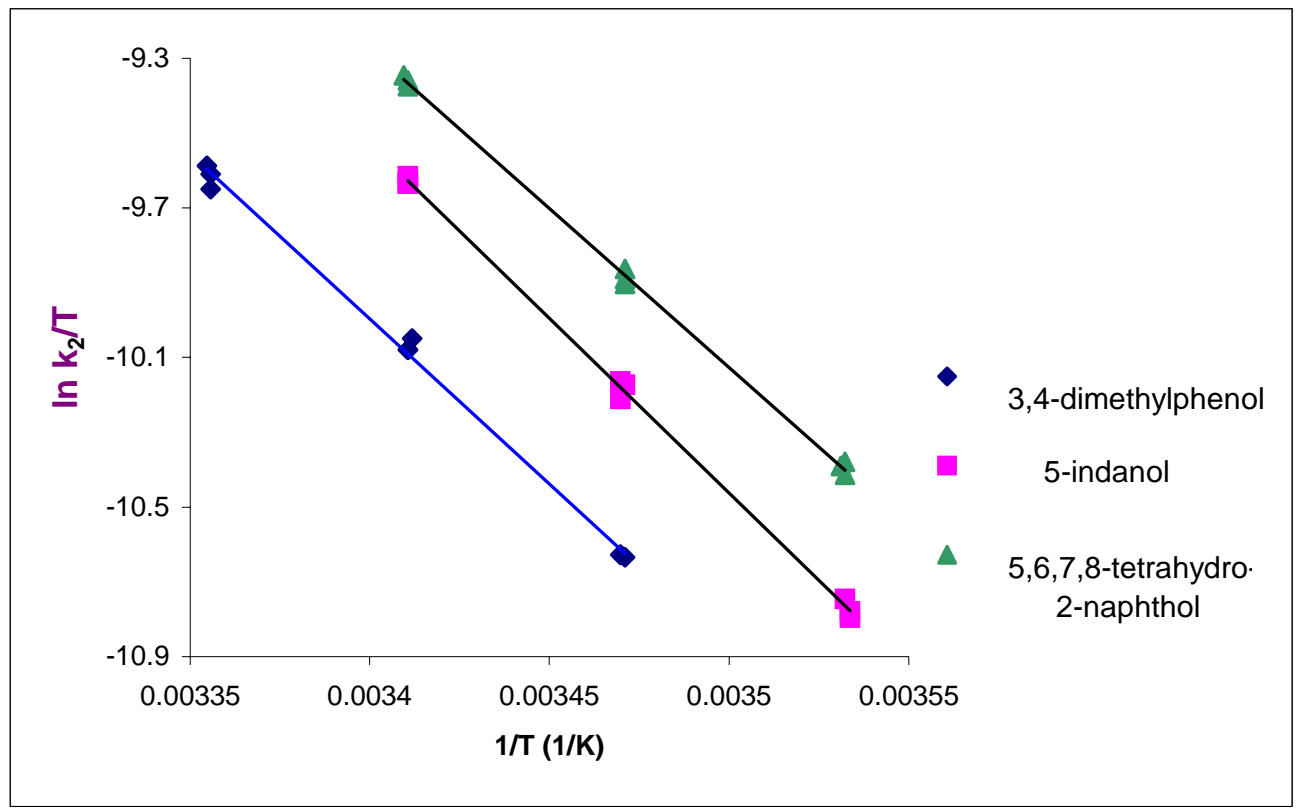




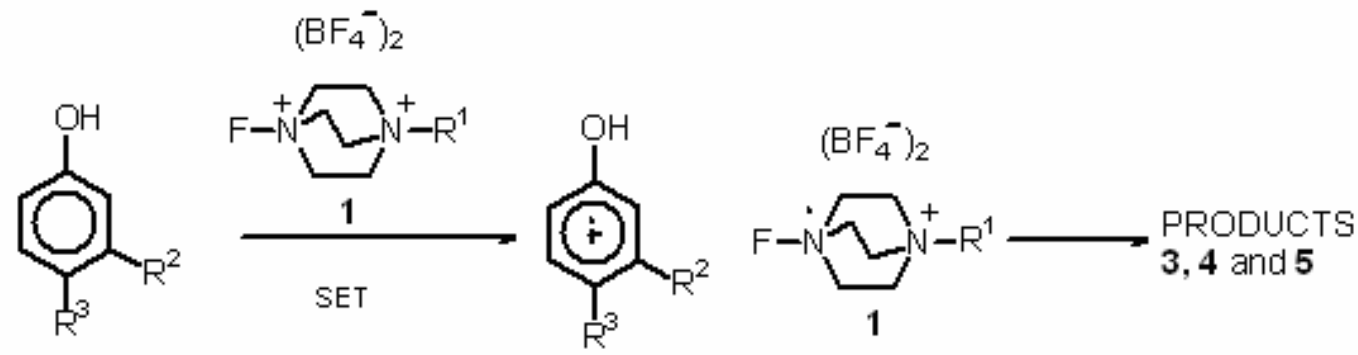

2

\section{Scheme}

\section{Experimental Section}

Materials. 1-Fluoro-4-chloromethyl-1,4-diazoniabicyclo[2.2.2] octane bis(tetrafluoroborate) (1a, Selectfluor $^{T M} \quad$ F-TEDA) and 1-fluoro-4-hydroxy-1,4-diazoniabicyclo[2.2.2] octane bis(tetrafluoroborate) (1b, Accufluor ${ }^{T M}$ NFTh, 50\% w/w on alumina) were obtained from commercial sources, and for synthetic application used as received. For kinetic measurements $F$ TEDA and NFTh were crystallised from an acetonitrile-methanol mixture and dried under reduced pressure before use. 3,4-Dimethylphenol (2a), 5-indanol (2b) and 5,6,7,8-tetrahydro-2naphthol (2c) from commercial sources were purified by crystallisation, acetonitrile was purified by distillation and stored over molecular sieves. KI and a standard solution of $\mathrm{Na}_{2} \mathrm{~S}_{2} \mathrm{O}_{3}$ from commercial sources were used as received. ${ }^{1} \mathrm{H}$ and ${ }^{19} \mathrm{~F}-\mathrm{NMR}$ spectra were obtained at $60 \mathrm{MHz}$ for proton and $56.4 \mathrm{MHz}$ for fluorine resonance in $\mathrm{CDCl}_{3}$ as solvent, and chemical shifts expressed in ppm from TMS or $\mathrm{CFCl}_{3}$ as internal standards.

\section{Fluorination of 3,4-dialkyl-substituted phenols 2a-c with F-TEDA or NFTh}

To a solution of $1 \mathrm{mmol}$ of substrate 2 in solvent $(10 \mathrm{~mL}), 0.354 \mathrm{~g}(1 \mathrm{mmol})$ of F-TEDA or 0.640 $\mathrm{g}(1 \mathrm{mmol}) \mathrm{NFTh}$ was added and the reaction mixture stirred at $20^{\circ} \mathrm{C}$ for 4.5 hours. The solvent was removed under reduced pressure, the crude reaction mixture dissolved in $\mathrm{CH}_{2} \mathrm{Cl}_{2}(40 \mathrm{~mL})$, and insoluble material filtered off. The solution was then washed with water $(40 \mathrm{~mL})$, dried over $\mathrm{Na}_{2} \mathrm{SO}_{4}$, and the solvent evaporated. The isolated crude reaction mixtures were analysed by ${ }^{1} \mathrm{H}$ and ${ }^{19} \mathrm{~F}-\mathrm{NMR}$, the amount of fluorinated products determined using octafluoronaphthalene as internal standard, and pure products obtained after separation by TLC $\left(\mathrm{SiO}_{2}, \mathrm{CH}_{2} \mathrm{Cl}_{2} / \mathrm{EtOH} 50 / 1\right)$. The spectroscopic data for the products $\mathbf{3 a},{ }^{6 \mathrm{c}} \mathbf{3} \mathbf{b},{ }^{10 \mathrm{~b}}$ and $\mathbf{3} \mathbf{c}^{10 \mathrm{~b}}$ were in agreement with the literature, while products $\mathbf{4}$ and $\mathbf{5}$ were identified on the basis of differences in their ${ }^{19} \mathrm{~F}-\mathrm{NMR}$ spectra, where compounds $\mathbf{5}$ are expressed as dd dignal with well defined ${ }^{3} \mathrm{~J}_{\mathrm{FH} 5}$ and ${ }^{4} \mathrm{~J}_{\mathrm{FH} 2}$ coupling constants, while compounds 4 shows due to the correlation of fluorine atom with alkyl protons a multiplet signal for F-2. 
2-Fluoro-3,4-dimethylphenol (4a) and 6-fluoro-3,4-dimethylphenol (5a). Yield 11\% of an oily mixture of both isomers in 1:2 relative ratio. ${ }^{1} \mathrm{H}-\mathrm{NMR}\left(60 \mathrm{MHz}, \mathrm{CDCl}_{3}\right): \delta 2.1\left(\mathrm{~s}, 6 \mathrm{H}, \mathrm{CH}_{3}\right)$, 6.6-7.1(m, 2H, $\mathrm{ArH}) ;{ }^{19} \mathrm{~F} \operatorname{nmr}\left(54.6 \mathrm{MHz}, \mathrm{CDCl}_{3}\right): 4 \mathbf{a}: \delta-147.3(\mathrm{~m})$ and 5a: $\delta-148.0(\mathrm{dd}$, ${ }^{3} \mathrm{~J}_{\mathrm{FH} 5}=11 \mathrm{~Hz},{ }^{4} \mathrm{~J}_{\mathrm{FH} 2}=9.5 \mathrm{~Hz}$ ); MS: $\mathrm{m} / \mathrm{z}$ calculated for $\mathrm{C}_{8} \mathrm{H}_{9} \mathrm{FO}: 140.0637$, measured: $140.0644 ; \mathrm{m} / \mathrm{z}$ : 140( $\left.\mathrm{M}^{+}, 95 \%\right), 125(100), 97(10), 91(24), 77(28)$.

4-Fluoro-5-indanol (4b) and 6-fluoro-5-indanol ${ }^{11}$ (5b). Yield 13\% of an oily mixture of both isomers in 1:6 relative ratio. ${ }^{1} \mathrm{H} \mathrm{nmr}\left(60 \mathrm{MHz}, \mathrm{CDCl}_{3}\right): \delta 1.8-2.6(\mathrm{~m}, 2 \mathrm{H}), 2.6-3.1(\mathrm{~m}, 4 \mathrm{H}), 6.6-$ 7.2(m, $2 \mathrm{H}) ;{ }^{19} \mathrm{~F} \operatorname{nmr}\left(54.6 \mathrm{MHz}, \mathrm{CDCl}_{3}\right): \mathbf{4 b}: \delta-148.2(\mathrm{~m})$ and $\mathbf{5 b}: \delta-146.7\left(\mathrm{dd},{ }^{3} \mathrm{~J}_{\mathrm{FH} 7}=11.3 \mathrm{~Hz}\right.$, $\left.{ }^{4} \mathrm{~J}_{\mathrm{FH} 4}=8.5 \mathrm{~Hz}\right) ; \mathrm{MS}: \mathrm{m} / \mathrm{z}$ calculated for $\mathrm{C}_{9} \mathrm{H}_{9} \mathrm{FO}: 152.0637$, measured: $152.0643 ; \mathrm{m} / \mathrm{z}: 152\left(\mathrm{M}^{+}\right.$, 97\%), 151(100), 133(53), 123(7), 103(32), 86(38), 84(61).

1-Fluoro-2-hydroxy-5,6,7,8-tetrahydronaphthalene (4c) and 3-fluoro-2-hydroxy-5,6,7,8tetrahydronaphthalene $(\mathbf{5 c})$. Yield $12 \%$ of an oily mixture of both isomers in 2:1 relative ratio. ${ }^{1} \mathrm{H} \mathrm{nmr}\left(60 \mathrm{MHz}, \mathrm{CDCl}_{3}\right): \delta$ 1.6-2.1(m, 4H), 2.3-3.0(m, 4H), 6.5-7.0(m, 2H); ${ }^{19} \mathrm{~F}$ NMR $(54.6$ $\left.\mathrm{MHz}, \mathrm{CDCl}_{3}\right): 4 \mathrm{~b}: \delta-149.5(\mathrm{~m})$ and $\left.5 \mathrm{~b}: \delta-147.8\left(\mathrm{dd},{ }^{3} \mathrm{~J}_{\mathrm{FH} 4}=18 \mathrm{~Hz},{ }^{4} \mathrm{~J}_{\mathrm{FH} 1}=15 \mathrm{~Hz}\right) ;\right) ; \mathrm{MS}: \mathrm{m} / \mathrm{z}$ calculated for ); MS: m/z calculated for $\mathrm{C}_{10} \mathrm{H}_{11} \mathrm{FO}: 166.0794$, measured: $166.0798 ; \mathrm{m} / \mathrm{z}: 166\left(\mathrm{M}^{+}\right.$, 75\%), 138(100), 125(25), 120(13), 109(16).

\section{Determination of reaction order and rate constants for reactions of hindered phenols with F-TEDA}

Various amounts ( $0.9 \mathrm{mmol}, 1.2 \mathrm{mmol}$ and $1.5 \mathrm{mmol}$ ) of starting phenols were dissolved in 40 $\mathrm{ml}$ of acetonitrile thermostatted at $15^{\circ} \mathrm{C}$. To each solution $0.6 \mathrm{mmol} \mathrm{F-TEDA} \mathrm{dissolved} \mathrm{in} 20 \mathrm{ml}$ of acetonitrile thermostatted at $15^{\circ} \mathrm{C}$ was added and the reaction mixtures further stirred at $15^{\circ} \mathrm{C}$. The progress of consumption of F-TEDA was monitored by iodometric titration. At different time intervals aliquots of $10 \mathrm{ml}$ were pumped off from the thermostatted reaction mixtures, treated with $20 \mathrm{ml}$ of $0.02 \mathrm{M} \mathrm{KI}$ and the liberated iodine titrated with $0.05 \mathrm{M} \mathrm{Na}_{2} \mathrm{~S}_{2} \mathrm{O}_{3}$. The consumption of F-TEDA followed a simple second order rate equation (1) and the second-order rate constants $\left(\mathrm{k}_{2}\right)$ collected in Table 3 were determined as the slope of the correlation plot (2), which always gave a straight line with a correlation coefficient higher than 0.98 . In eq. 2

$$
\ln \left(\mathbf{c}_{\mathrm{B} 0} \mathbf{c}_{\mathrm{A}} / \mathbf{c}_{\mathrm{A} 0} \mathbf{c}_{\mathrm{B}}\right) /\left(\mathbf{c}_{\mathrm{A} 0}-\mathbf{c}_{\mathrm{B} 0}\right)=\mathbf{k}_{2} \mathrm{t}
$$

where $c_{A 0}$ and $c_{B 0}$ are the initial concentrations of the reagent (F-TEDA) and the substrate (phenol), respectively, and $\mathrm{c}_{\mathrm{A}}$ and $\mathrm{c}_{\mathrm{B}}$ are the concentrations of the reagent and substrate, respectively, after time t. The values for $k_{2}$ collected in Table 3 and Table 4 are averages from at least three measurements with no more than $3 \%$ relative error.

\section{Determination of the thermodynamic parameters of the transition state for the reaction of hindered phenols with F-TEDA}

Second order reaction constants $\left(\mathrm{k}_{2}\right)$ for the reactions of target phenols with F-TEDA at different reaction temperatures were measured as described above. The relation of $\mathrm{k}_{2}$ with temperature derived from the Eyring equation 


$$
\ln \left(\mathbf{k}_{2} / \mathbf{T}\right)=\ln \left(\mathbf{k}_{\mathbf{B}} / \mathbf{h}\right)+\Delta \mathbf{S}^{\ddagger} / \mathbf{R}-\Delta \mathbf{H}^{\ddagger} / \mathbf{R T}
$$

was found to follow a straight line with a correlation coefficient better than 0.98 . The free energy of activation $\Delta \mathrm{G}^{\#}$ was calculated from the relation $\Delta \mathrm{G}^{\#}=\Delta \mathrm{H}^{\#}-\mathrm{T} \Delta \mathrm{S}^{\#}$.

\section{Acknowledgements}

The authors are grateful to the Ministry of Education, Science and Sport of the Republic of Slovenia for financial support (Contract number: PO 0545-0106).

\section{References and Notes}

1. (a) Lal, G.S; Pez, G.P.; Syvret, R.G. Chem. Rev. 1996, 96, 1737. (b) Taylor, S.D.; Kotoris, C.C.; Hum, G. Tetrahedron 1999, 55, 12431. (c) Furin, G.G.; Fainzilberg, A.A. Russian Chem. Rev. 1999, 68, 653.

2. (a) Baasner, B.; Hagemann, H.; Tatlow, J.C.; Eds.; Methods of Organic Chemistry (HoubenWeyl) Vol. E 10a and 10b: Organofluorine Compounds; Thieme: New York, 1999. (b) Hudlicky, M., Pavlath, A.E., Eds.; Chemistry of Organic Fluorine Compounds II. A Critical Review. ACS Monograph 187. ACS: Washington DC, 1995. (c) Hiyama T. Organofluorine Compounds. Chemistry and Applications; Springer-Verlag: Berlin, 2000.

3. (a) Banks, R.E.; Mohialdin-Khaffaf, S.N.; Lal, S.G.; Sharif, I.; Syvret, R.G. J. Chem. Soc., Chem. Commun. 1992, 595. (b) Stavber, S.; Zupan, M.; Poss, A.J.; Shia, G.A. Tetrahedron Lett. 1995, 36, 6769. (c) Umemoto, T.; Nagayoshi, M. Bull. Chem. Soc. Jpn. 1996, 69, 2287.

4. (a) Gilicinski, A.G.; Pez, G.P.; Syvret, R.G.; Lal, G.S. J. Fluorine Chem. 1992, 59, 157. (b) Differding, E.; Bersier, P.M. Tetrahedron 1992, 48, 1595.

5. Girina, G.P.; Faizil'berg, A.A.; Feoktistov, L.G. Russ. J. Electrochem. 2000, 36, 162.

6. (a) Zupan, M.; Iskra, J.; Stavber, S. Bull. Chem. Soc. Jpn. 1995, 68, 1655. (b) Stavber, S.; Zupan, M. Synlett 1996, 693. (c) Stavber, S.; Jereb, M.; Zupan, M. Synlett 1999, 1375. (d) Stavber, S.; Jereb, M.; Zupan, M. ARKIVOC 2001, (v), 98. (e) Stavber, S.; Jereb, M.; Zupan, M. J. Phys. Org. Chem. 2002, 15, 56.

7. Mills, W.H.; Nixon, I.G. J. Chem. Soc. 1930, 2510.

8. (a) Nilsson, J.L.G.; Selander, H.; Sievertsson, H.; Skanberg, I.; Svensson, K.G. Acta Chim. Scand. 1971, 25, 94. (b) Tee, O. S.; Iyegar, N.R.; Bennett, J.M. J. Org. Chem. 1986, 51, 2585.

9. (a) Bergquist, K.E.; Nilsson, A.; Ronlan, A. Acta Chim. Scand. 1982, 36, 675. (b) Nilsson, A.; Ronlan, A.; Parker, V.D. Tetrahedron Lett. 1975, 16,1107. (c) Ferron, B.; Jacquesy, J.C.; Jouannetaud, M.P.; Karam, O.; Coustard, J.M. Tetrahedron Lett. 1993, 34, 2949. 
10. (a) Meuers, J.H.H.; Sopher, D.W.; Eilenberg, W. Angew. Chem. 1989, 101, 955. (b) Karam, O.; Jacquesy, J.C.; Jouannetaud, M.P. Tetrahedron Lett. 1994, 35, 2541.

11. Kikimuto, R.; Tobe, A.; Fukami, H.; Egawa, M. J. Med .Chem. 1983, 26, 246.

12. Vaughan, J.; Wright, J.G. J. Org. Chem. 1968, 33, 2580. 